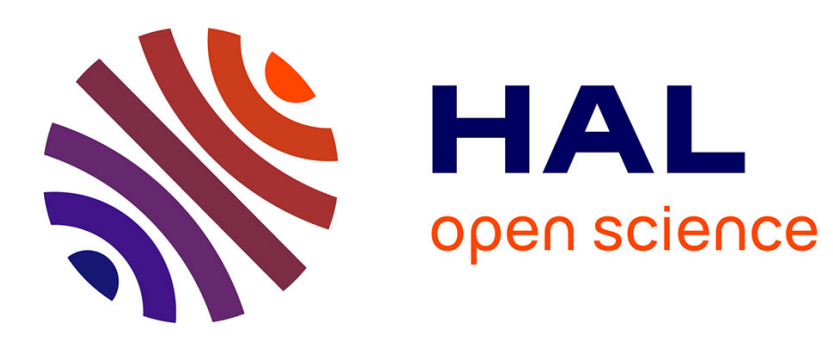

\title{
Experimental Study on the Nonlinear Vibrations and $n x$ Amplitudes of a Rotor With a Transverse Crack Jean-Jacques Sinou
}

\section{To cite this version:}

Jean-Jacques Sinou. Experimental Study on the Nonlinear Vibrations and nx Amplitudes of a Rotor With a Transverse Crack. Journal of Vibration and Acoustics, 2009, 131 (4), pp.041008. 10.1115/1.3086928 . hal-00411751

\section{HAL Id: hal-00411751 \\ https://hal.science/hal-00411751}

Submitted on 1 Oct 2018

HAL is a multi-disciplinary open access archive for the deposit and dissemination of scientific research documents, whether they are published or not. The documents may come from teaching and research institutions in France or abroad, or from public or private research centers.
L'archive ouverte pluridisciplinaire HAL, est destinée au dépôt et à la diffusion de documents scientifiques de niveau recherche, publiés ou non, émanant des établissements d'enseignement et de recherche français ou étrangers, des laboratoires publics ou privés. 
In this paper, the nonlinear response of a rotor system containing a transverse crack is analyzed experimentally in order to propose a nondestructive detection of cracks in the rotor. More particularly, the evolutions of the $n \times$ superharmonic frequency components at the various subcritical resonant peaks and the decrease in the subcritical resonant speeds are investigated for various crack depths. The experimental results that are presented in this study confirm the theoretical analysis of many researchers and provide a possible basis for an on-line monitoring system.

\section{Introduction}

Due to the fact that propagating fatigue transverse cracks can have catastrophic effects on the reliability of the rotating machinery, an early detection of cracks (i.e., before the crack had propagated to a critical depth) appears obvious and has been a subject of great interest for the past 30 years. So, considerable efforts have been undertaken to develop and to propose robust indicators and reliable strategies to detect cracks in rotors before the occurrence of a catastrophic failure. Extensive surveys of the dynamic behavior of cracked rotors are given in Refs. [1-4], and many researchers have studied the dynamic behavior of rotors with transverse crack by considering experimental and/or numerical studies [5-10].

For example, Darpe et al. [5] proposed to study experimentally a cracked rotor that is subjected to external axial excitation. They concluded that the detection can be based on the presence of axial frequencies in the lateral vibration spectra that confirm the coupling of bending and longitudinal vibrations. For an uncracked rotor, the presence of these axial frequencies in the lateral vibration spectra is not existent or marginal. Ishida and Inoue [7] investigated the nonlinear vibration using harmonic excitation force to detect a rotor crack without stopping the rotor system during on-line operation. They observed that nonlinear resonances occur due to the nonlinear parametric excitation characteristics of the cracked rotor.

Then, several authors $[6,8-10]$ have paid their attention to the changes in vibration characteristics and $1 \times, 2 \times$, and $3 \times$ components of rotor vibration. However, it is well known that the presence of $2 \times$ harmonic frequency components is not sufficient to indicate the presence of a crack in the rotor and that these changes can be small and difficult to detect $[6,10]$. So, in the present study, the evolutions of the $1 \times, 2 \times, 3 \times$, and $4 \times$ harmonic components at subcritical resonances are analyzed for different crack depths and rotor unbalances in order to find robust indicators of crack detection and monitoring techniques.

This paper is organized as follows. First the experimental test rig with the cracked rotor under study is described in Sec. 2. Then, the experimental studies and a nondestructive detection of a transverse crack for a rotor system based on the presence and evolution

\footnotetext{
${ }^{1}$ Corresponding author.
}

of the $n \times$ superharmonic frequency components and the decrease in the subcritical resonant speeds are presented in Sec. 3.

\section{Experimental Setup}

Figure 1 illustrates the experimental rig designed to investigate the effects of crack on the nonlinear rotor behavior. The rotor that is composed of an elastic shaft and a disk is simply supported at both ends. It is driven by an electric motor, which is connected through a laterally flexible and torsionally rigid coupling. The length of the shaft is $480 \mathrm{~mm}$ and its diameter is $10 \mathrm{~mm}$. The disk is mounted at the position $382 \mathrm{~mm}$ from the left end of the rotor. The diameter and thickness of the disk-rotor are $75 \mathrm{~mm}$ and $35 \mathrm{~mm}$, respectively. The rotor's cracks are made at the position $243 \mathrm{~mm}$ by cutting a piece with width $0.8 \mathrm{~mm}$ and various nondimensional depths (from $\mu=0$ to $\mu=1$ ). Each cutting is realized on the complete rotor without dismantling operations in order to be able to detect the combined effects of the crack depth and the unbalance on the nonlinear dynamic of the rotor system.

The vibration measurements are conducted by using six proximity probes that are mounted in both the horizontal and vertical directions, as indicated in Fig. 1. They consist of two orthogonal sensors for each plane and are placed at $70 \mathrm{~mm}$ (plane A1), $210 \mathrm{~mm}$ (plane A2), and $440 \mathrm{~mm}$ (plane A3) from the left end of the shaft. Planes A1 and A3 are situated near the left and right supports, respectively, and plane A2 is at the middle of the shaft (near the crack position, as indicated in Fig. 1).

The rotor speed is measured and monitored at regular intervals during the tests, and a variability of $5 \mathrm{rpm} / \mathrm{s}$ is chosen during run-ups.

\section{Experimental Results}

In this section, experimental tests are undertaken in order to study the influences of the nondimensional crack depth for $\mu=0$ (i.e., uncracked rotor) to $\mu=1$ (which corresponds to the case of half the area of the cross section is missing due to the transverse crack). For the sake of clarity and in order to identify clearly the effects of a transverse crack on the evolutions of the $n \times$ amplitudes, the amplitudes of each sensor will be normalized on the speed range under study as follows:

$$
X_{\text {normalized }}=\frac{\log (X)-\log \left(X_{\min }\right)}{\log \left(X_{\max }\right)-\log \left(X_{\min }\right)}
$$

where $X_{\min }$ and $X_{\max }$ define the minimum and maximum amplitudes for the considered sensor. It may be noted that the physical 


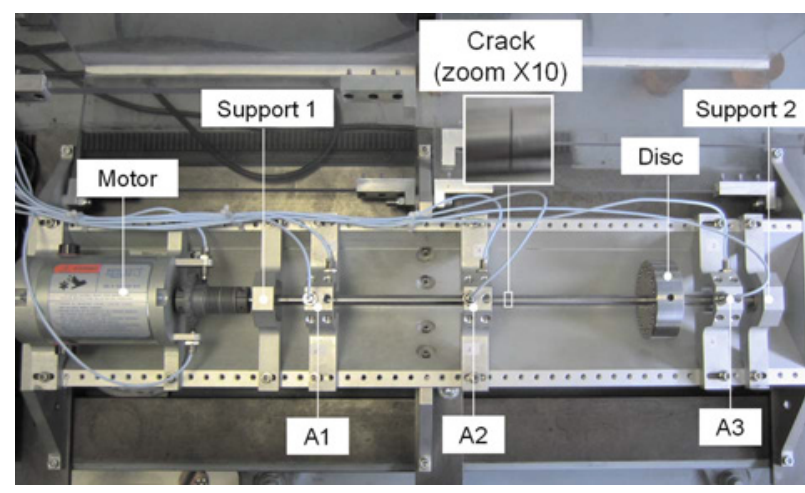

Fig. 1 Experimental system with the crack position

values of $n \times$ vertical and horizontal amplitudes will be given in Tables 1-4.

Figures 2 and 3 show the imbalance response curves of the rotor system for various crack depths in the vertical direction with $1 \times$ amplitudes dominating. Tables 1 and 2 give the maximum horizontal and vertical $1 \times$ amplitudes, respectively. In the considered range of rotating speeds, only the first critical speeds on the horizontal and vertical directions of the rotor system are observed (around 2600-2800 rpm). As previously explained by a lot of researchers $[1,6,10,11]$, the $1 \times$ and $2 \times$ vibration amplitudes are
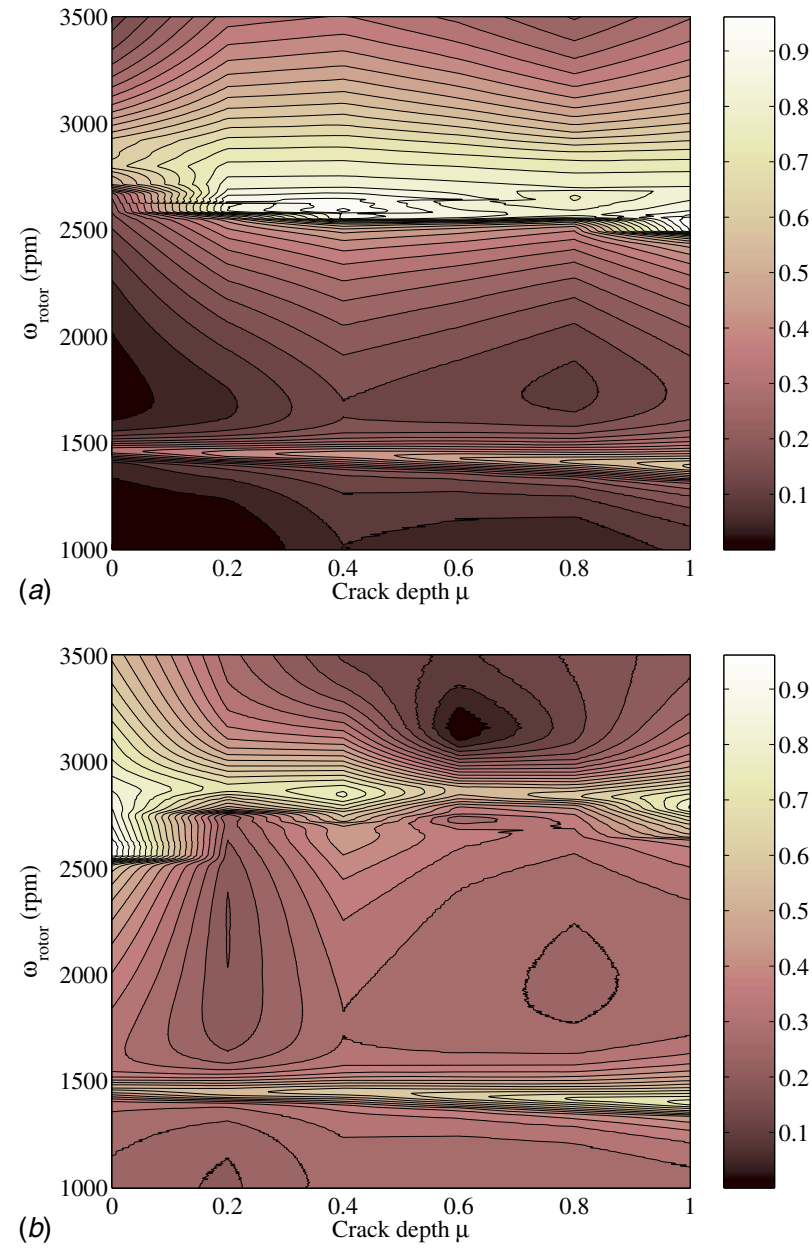

Fig. 2 Evolutions of the nonlinear vertical amplitudes (plane A3) of the cracked rotor for various crack depths and unbalances' configurations: (a) $0 \mathrm{gm}$ and (b) $0.4 \mathrm{gm}$
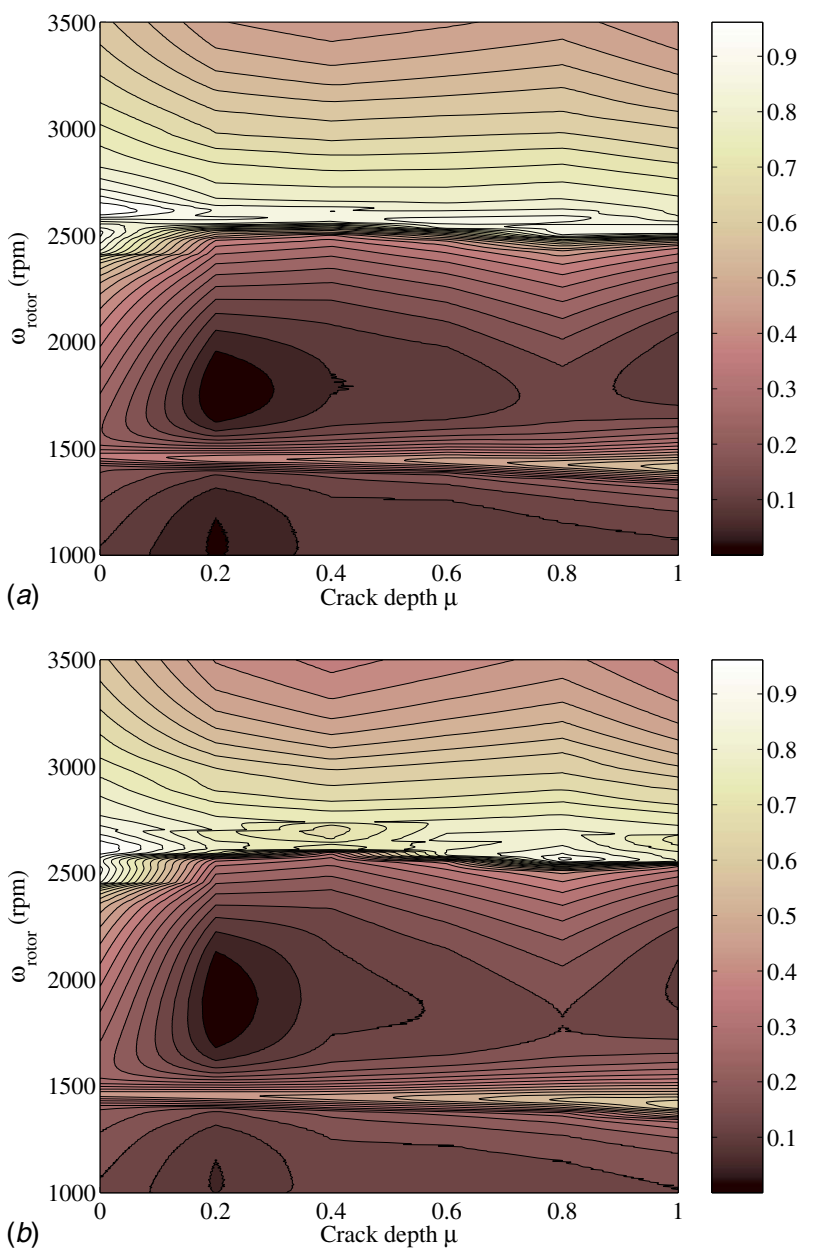

Fig. 3 Evolutions of the nonlinear vertical amplitudes (plane A3) of the cracked rotor for various crack depths and unbalances' configurations: (a) $0.8 \mathrm{gm}$ and (b) $1 \mathrm{gm}$

presented and prominent in both the vertical and horizontal directions of all the measured vibrations due to the presence of the crack.

Effectively, the motion of the rotor is complicated due to the existence of the $2 \times$ superharmonic frequency components in the horizontal and vertical vibration signals at rotating speeds of

Table $11 \times$ horizontal amplitudes at the first critical speed for various unbalances and crack depths (in micrometers)

\begin{tabular}{|c|c|c|c|c|c|c|c|}
\hline $\begin{array}{l}\text { Unbalance } \\
(\mathrm{gm})\end{array}$ & Sensor & $\mu=0$ & $\mu=0.2$ & $\mu=0.4$ & $\mu=0.6$ & $\mu=0.8$ & $\mu=1$ \\
\hline \multirow[t]{3}{*}{0} & A1 & 44 & 95 & 114 & 96 & 90 & 166 \\
\hline & A2 & 68 & 182 & 217 & 181 & 170 & 313 \\
\hline & A3 & 35 & 100 & 117 & 87 & 83 & 172 \\
\hline \multirow[t]{3}{*}{0.4} & A1 & 99 & 45 & 57 & 40 & 19 & 64 \\
\hline & A2 & 179 & 82 & 109 & 74 & 28 & 115 \\
\hline & A3 & 108 & 28 & 42 & 26 & 8 & 43 \\
\hline \multirow[t]{3}{*}{0.8} & $\mathrm{~A} 1$ & 273 & 73 & 74 & 69 & 106 & 71 \\
\hline & A2 & 475 & 129 & 127 & 121 & 188 & 127 \\
\hline & A3 & 276 & 71 & 63 & 69 & 117 & 71 \\
\hline \multirow[t]{3}{*}{1} & A1 & 347 & 117 & 112 & 135 & 192 & 155 \\
\hline & A2 & 618 & 207 & 197 & 240 & 344 & 276 \\
\hline & A3 & 344 & 124 & 120 & 147 & 207 & 166 \\
\hline
\end{tabular}


Table $21 \times$ vertical amplitudes at the first critical speed for various unbalances and crack depths (in micrometers)

\begin{tabular}{lccccccc}
\hline \hline $\begin{array}{l}\text { Unbalance } \\
(\mathrm{gm})\end{array}$ & Sensor & $\mu=0$ & $\mu=0.2$ & $\mu=0.4$ & $\mu=0.6$ & $\mu=0.8$ & $\mu=1$ \\
\hline 0 & $\mathrm{~A} 1$ & 52 & 108 & 118 & 92 & 79 & 126 \\
& $\mathrm{~A} 2$ & 106 & 253 & 273 & 212 & 185 & 298 \\
& $\mathrm{~A} 3$ & 60 & 170 & 186 & 140 & 113 & 207 \\
0.4 & $\mathrm{~A} 1$ & 103 & 41 & 49 & 21 & 25 & 62 \\
& $\mathrm{~A} 2$ & 219 & 100 & 126 & 56 & 49 & 150 \\
& $\mathrm{~A} 3$ & 160 & 47 & 64 & 25 & 32 & 73 \\
& & & & & & & \\
0.8 & $\mathrm{~A} 1$ & 142 & 81 & 73 & 82 & 109 & 78 \\
& $\mathrm{~A} 2$ & 303 & 166 & 144 & 169 & 228 & 159 \\
& $\mathrm{~A} 3$ & 220 & 103 & 88 & 117 & 170 & 104 \\
& & & & & & & \\
& $\mathrm{~A} 1$ & 167 & 114 & 107 & 119 & 121 & 116 \\
& $\mathrm{~A} 2$ & 360 & 240 & 222 & 252 & 246 & 253 \\
& $\mathrm{~A} 3$ & 260 & 177 & 166 & 189 & 186 & 189 \\
\hline \hline
\end{tabular}

nominally $\frac{1}{2}$ times the synchronous critical speed (at $1500 \mathrm{rpm}$ ). This fact is illustrated in Fig. 4 . The maximum $2 \times$ horizontal and vertical order components are drastically affected by the variation in the crack depth, as indicated in Tables 3 and 4. Increasing the crack depth increases the $\frac{1}{2}$ subcritical resonant peaks whereas the associated $\frac{1}{2}$ subcritical resonant speed decreases. It may be observed that the variations in the resonant peaks and speeds are important in both the horizontal and vertical directions and it should be possible to use these changes to detect the existence of a crack. These results may be clearly interpreted as the contribution of the reduced stiffness, which changes the system natural frequencies, resulting from the presence of the crack, and agree with the results reported by Gasch [1], Davies and Mayes [8,9], Adewusi and Al-Bedoor [10], and Sinou and Lees [11,12].

Moreover, at the $\frac{1}{2}$ subharmonic resonances, amplitudes of the $2 \times$ harmonic frequency components have been generally found to be stronger in the vertical direction than in the horizontal direction for various crack depths and rotor unbalances, as indicated in Tables 3 and 4. These experimental results confirm the numerical investigations of Sinou and Lees [11,12]. However, it may be noted that Darpe et al. [5] found that the harmonic components in the horizontal direction are stronger than in the vertical direction during the passage through subharmonic resonances (for a Jeffcott rotor with a disk mounted at midspan). So, the comparisons of the
Table $32 \times$ horizontal amplitudes at one-half of the first critical speed for various unbalances and crack depths (in micrometers)

\begin{tabular}{lccccccc}
\hline \hline $\begin{array}{l}\text { Unbalance } \\
(\mathrm{gm})\end{array}$ & Sensor & $\mu=0$ & $\mu=0.2$ & $\mu=0.4$ & $\mu=0.6$ & $\mu=0.8$ & $\mu=1$ \\
\hline 0 & $\mathrm{~A} 1$ & 21 & 24 & 29 & 33 & 38 & 44 \\
& $\mathrm{~A} 2$ & 37 & 43 & 49 & 56 & 62 & 74 \\
& $\mathrm{~A} 3$ & 15 & 17 & 20 & 23 & 25 & 31 \\
& & & & & & & \\
0.4 & $\mathrm{~A} 1$ & 18 & 25 & 30 & 35 & 40 & 46 \\
& $\mathrm{~A} 2$ & 32 & 45 & 52 & 59 & 65 & 78 \\
& $\mathrm{~A} 3$ & 13 & 18 & 21 & 24 & 26 & 32 \\
0.8 & & & & & & & \\
& $\mathrm{~A} 1$ & 4 & 7 & 12 & 14 & 13 & 24 \\
& $\mathrm{~A} 2$ & 8 & 13 & 20 & 25 & 25 & 44 \\
& $\mathrm{~A} 3$ & 5 & 7 & 9 & 11 & 11 & 18 \\
1 & & & & & & & \\
& $\mathrm{~A} 1$ & 20 & 26 & 32 & 34 & 40 & 44 \\
& $\mathrm{~A} 2$ & 36 & 46 & 54 & 59 & 67 & 76 \\
& $\mathrm{~A} 3$ & 15 & 19 & 22 & 24 & 27 & 32 \\
\hline \hline
\end{tabular}

harmonic components in the horizontal and vertical directions cannot be used as robust indicators for the detection of a transverse crack in the rotor.

Then, Fig. 4 shows the presence of the $2 \times$ superharmonic frequency components for the uncracked rotor (for $\mu=0$ ). This small amount of $2 \times$ component present in the lateral vibrations should be caused by several other mechanisms that may generate $2 \times$ harmonic frequency component, such as the bow-related side load on the shaft, the rotor anisotropy, and the unbalance. This feature is well known and clearly indicates that the presence of $2 \times$ harmonic components is not sufficient to be considered as a reliable indicator of the presence of a crack in the rotor.

It may be noted that the $\frac{1}{2}$ th order subcritical resonance is not only caused by the second order superharmonic frequency component but also by the $3 \times$ and $4 \times$ superharmonic frequency components that are present in both the horizontal and vertical directions (as illustrated in Fig. 5). However, the amplitudes of the 2 $\times$ are greater than that of the $3 \times$ or $4 \times$ (the maximum amplitudes of the third and fourth are not greater than $10 \mu \mathrm{m})$. Then, the rotating speed where $3 \times$ and $4 \times$ the maximum amplitudes appear decreases with the increase in the crack depth. Finally, with the increase in the crack depth, the $3 \times$ and $4 \times$ superharmonic frequency components increase.
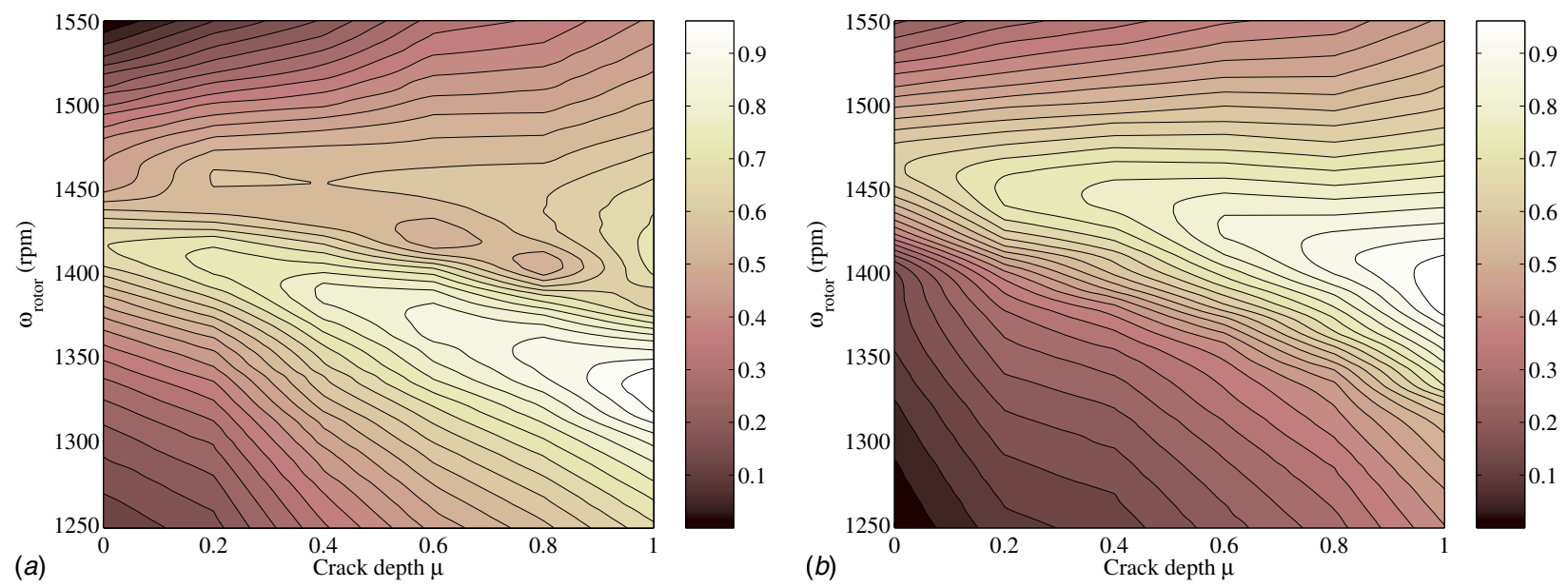

Fig. 4 Evolutions of the $2 \times$ superharmonic frequency components (plane A3) at the $\frac{1}{2}$ subcritical resonant speed: (a) normalized horizontal amplitudes and $(b)$ normalized vertical amplitudes 
Table $42 \times$ vertical amplitudes at one-half of the first critical speed for various unbalances and crack depths (in micrometers)

\begin{tabular}{lccccccc}
\hline \hline $\begin{array}{l}\text { Unbalance } \\
\text { (gm) }\end{array}$ & Sensor & $\mu=0$ & $\mu=0.2$ & $\mu=0.4$ & $\mu=0.6$ & $\mu=0.8$ & $\mu=1$ \\
\hline 0 & A1 & 13 & 19 & 21 & 27 & 35 & 47 \\
& A2 & 36 & 49 & 54 & 68 & 82 & 106 \\
& A3 & 20 & 26 & 30 & 36 & 44 & 56 \\
0.4 & A1 & 16 & 19 & 21 & 27 & 37 & 47 \\
& A2 & 42 & 48 & 54 & 67 & 86 & 106 \\
& A3 & 23 & 26 & 30 & 36 & 45 & 56 \\
& & & & & & & \\
0.8 & A1 & 2 & 2 & 3 & 4 & 5 & 8 \\
& A2 & 6 & 8 & 9 & 12 & 15 & 24 \\
& A3 & 4 & 5 & 5 & 7 & 8 & 11 \\
1 & A1 & 13 & 19 & 21 & 26 & 34 & 47 \\
& A2 & 35 & 49 & 53 & 66 & 82 & 108 \\
& A3 & 19 & 26 & 28 & 35 & 43 & 56 \\
\hline \hline
\end{tabular}

It may be noted that the horizontal and vertical maximum amplitudes of the $2 \times, 3 \times$, and $4 \times$ orders grow gradually with the nondimensional crack depth at the $\frac{1}{2}$ subcritical resonant speed (as illustrated in Figs. 4 and 5). Moreover, Tables 3 and 4 clearly indicate that increasing the crack depth increases the $2 \times$ ampli- tudes even if the rotor unbalance is modified. So it may be concluded that the evolutions of the $2 \times, 3 \times$, and $4 \times$ superharmonic frequency components at one-half of the first critical speed are global robust indicators for a nondestructive detection of a transverse crack in rotors. All these experimental results of the nonlinear dynamic behavior of a cracked rotor and the evolutions of the $n$th orders at one-half of the first critical speed agree very well with the theoretically and numerically analysis that has been done by Sinou $[13,14]$.

Moreover, with the increase in the crack depth, the $\frac{1}{3}$ subcritical resonant peaks increase due to the presence of the $3 \times$ superharmonic frequency components, as shown in Fig. 6. All these results are consistent with the numerical results reported in the previous numerical studies of Sinou and Lees [11,12].

So it may be concluded that all these evolutions of $n \times$ superharmonic frequency components at various $1 / \mathrm{m}$ subcritical resonant speeds (with $n \geqslant m$ ) may be very interesting for the detection of the presence of a crack and in evaluating the propagation of a transverse crack in rotor systems. However, only using the high order harmonics components should be more difficult due to the small evolutions of amplitudes with increasing crack depth.

Showing all these experimental results (not only the effects of the crack depth on the $n$th order of the subcritical resonant peaks but also the interactions between the crack depth and the unbalance), it may be concluded that a reference situation of the rotor system (without crack if possible) and in the same operating con-
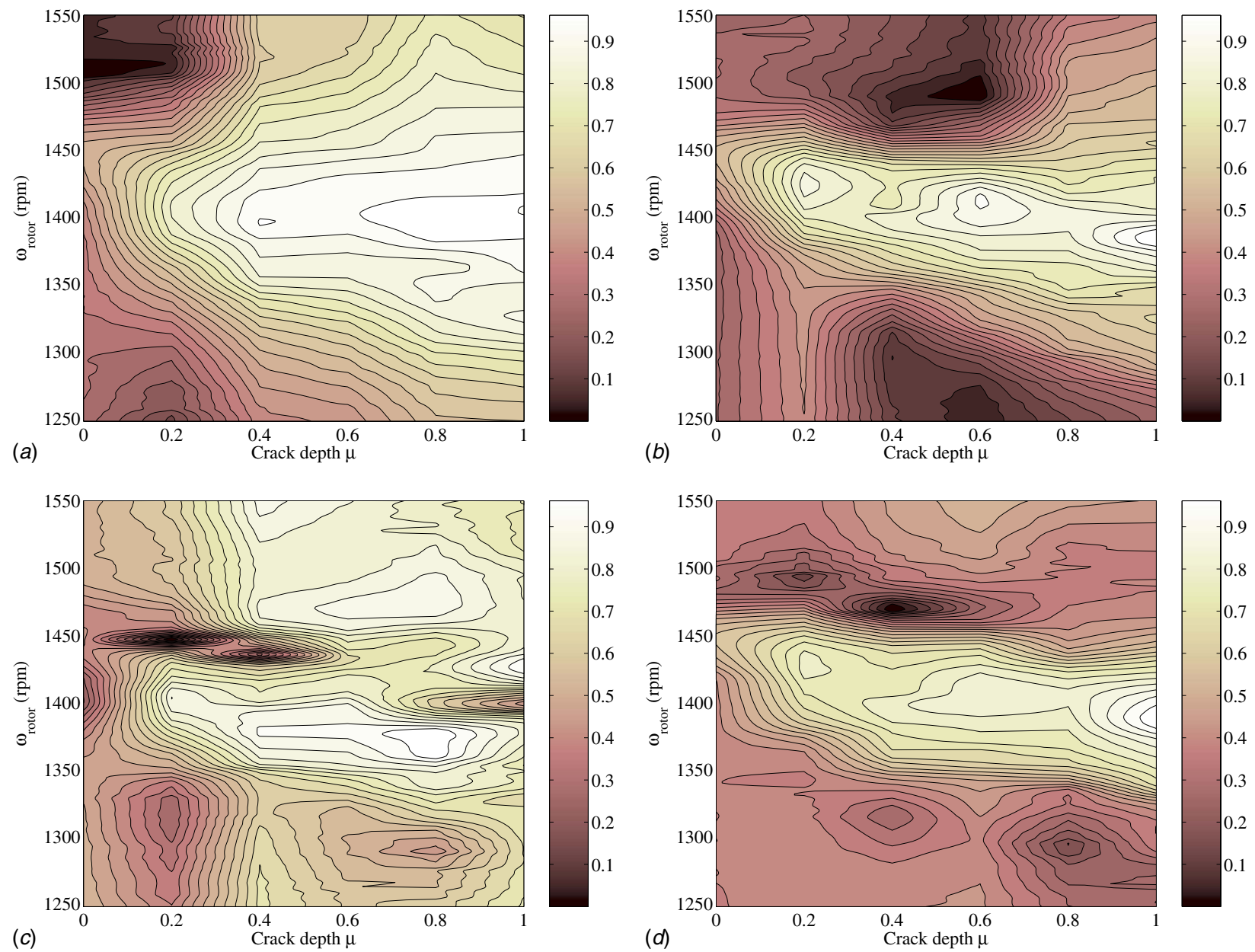

Fig. 5 Evolutions of the $3 \times$ and $4 \times$ superharmonic frequency components at the $\frac{1}{2}$ subcritical resonant speed: (a) plane A1-order $3 \times-$ normalized horizontal amplitude, (b) plane A1-order $3 \times$-normalized vertical amplitude, (c) plane A1order $4 \times$-normalized horizontal amplitude and (d) plane $A 1-$ order $4 \times$-normalized vertical amplitude 

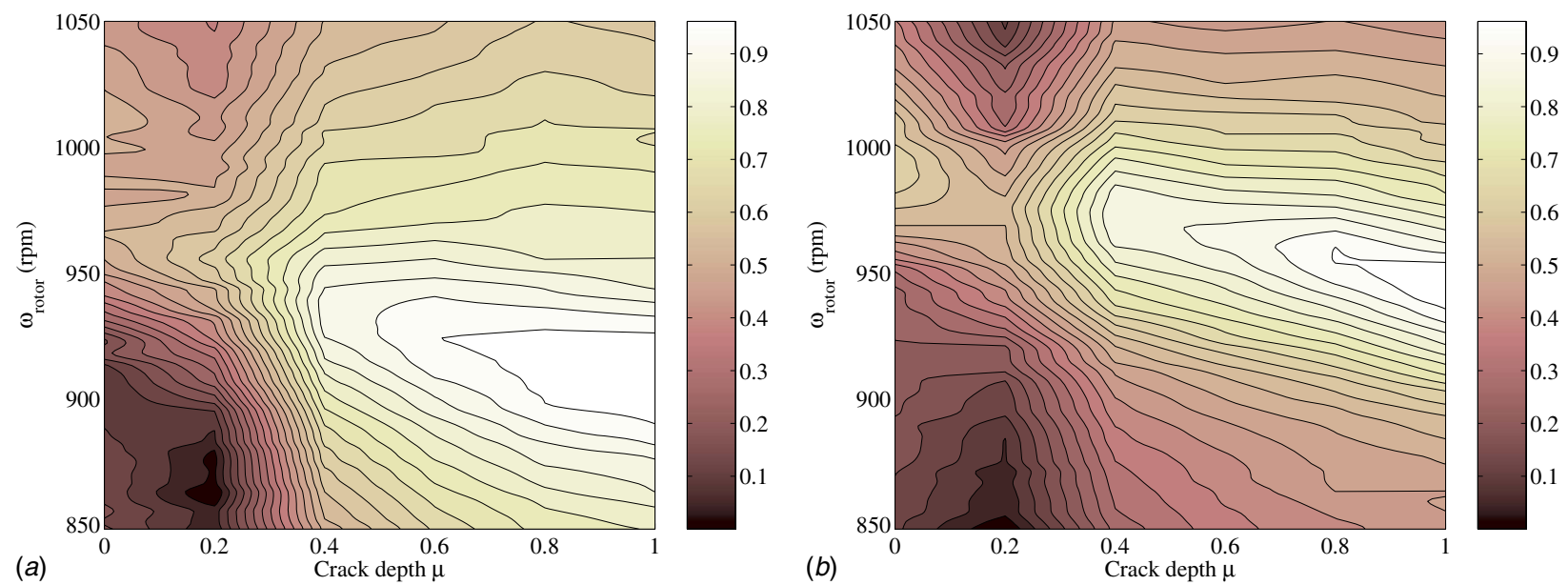

Fig. 6 Evolutions of the $3 \times$ superharmonic frequency components at the $\frac{1}{3}$ subcritical resonant speed: (a) plane A2-order $3 \times-$ normalized horizontal amplitude and (b) plane A2-order $3 \times$-normalized vertical amplitude
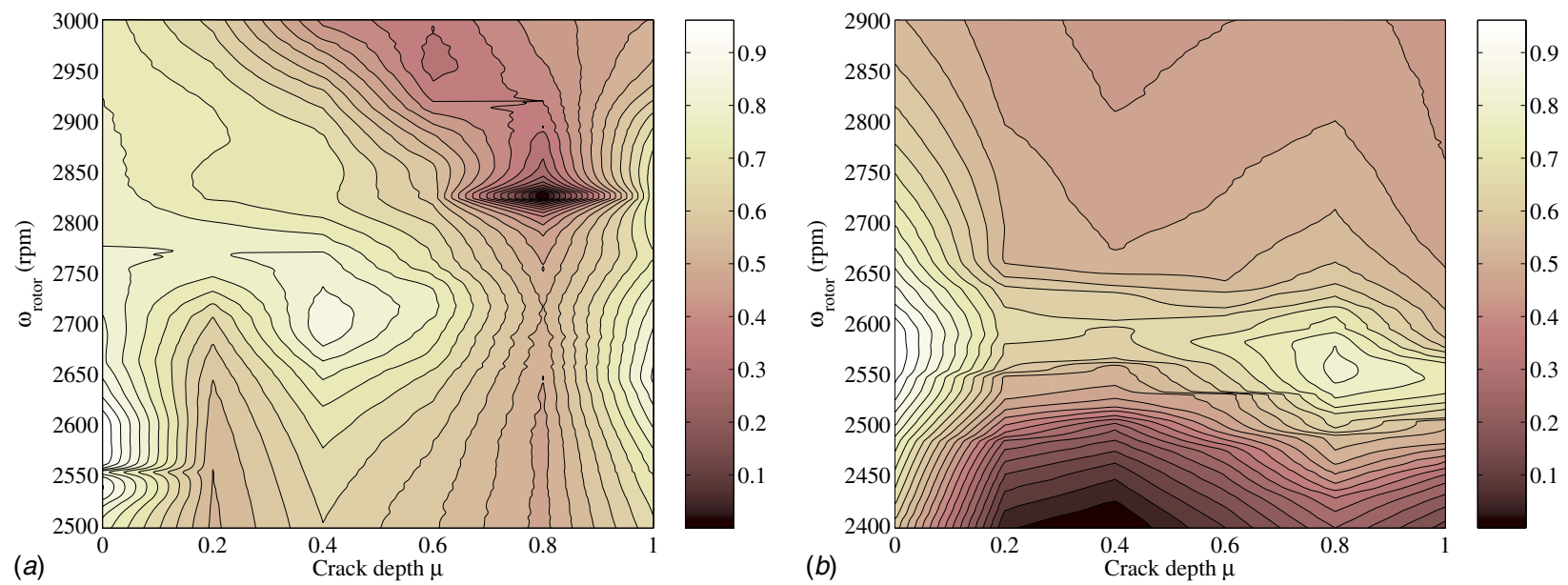

Fig. 7 Evolutions of the $1 \times$ superharmonic frequency components at the first critical speed for various unbalance: (a) plane A2-order $1 \times$-normalized horizontal amplitude-unbalance $0.4 \mathrm{gm}$ and (b) plane A2-order $1 \times$-normalized horizontal amplitude-unbalance $1 \mathrm{gm}$

ditions is necessary in order to clearly evaluate the change in vibrations and $n \times$ superharmonic frequency components due to the propagation of a transverse crack.

Then, it may be shown that the nondimensional crack depth affects the value of the maximum vertical and horizontal amplitudes when the rotating speed passes through the first critical speed (see, for example, Figs. 2 and 3). However, Fig. 7 indicates that the $1 \times$ amplitudes may increase or decrease with the increase in the crack depth (while the $2 \times$ and $3 \times$ amplitudes always increase). This is only due to the fact that the $1 \times$ horizontal and vertical amplitudes depend on the interaction between the crack depth and the rotor's unbalance: For an unbalance of $0.4 \mathrm{gm}$, the minimum amplitude is obtained for $\mu=0.4$, whereas the minimum amplitude is observed at $\mu=0.8$ if the unbalance is $1 \mathrm{gm}$, as indicated in Figs. 7(a) and 7(b) and Tables 1 and 2.

\section{Conclusion}

Experimental results on the dynamic response of a rotor with various cracks are presented. The study shows that the presence of a crack excites $2 \times$ and $3 \times$ vibration harmonics at the $\frac{1}{2}$ and $\frac{1}{3}$ subcritical resonant speeds, respectively. So the evolutions of the maximum amplitudes of the rotating speed around one-third and one-half of the first critical speed could be used in order to detect the presence and signature of a crack.

Moreover, the results indicate that the $2 \times$ and $3 \times$ amplitudes increase with the crack growth whereas the $1 \times$ amplitudes may increase or decrease at the first critical speed. Then, the $n \times$ superharmonic frequency components are significant at the $m$ th subcritical resonance (with $n \geqslant m$ ). It may be concluded that the changes in amplitudes of the $1 \times, 2 \times$, and $3 \times$ vibration harmonics could also be investigated in order to detect the presence and propagation of a crack in the rotor system.

Even if the evolution of the $n \times$ amplitudes are efficient indicators of the presence of a transverse crack and can be used to improve the accuracy of vibration-based crack detection techniques, it may be noted that the presence of a crack in the rotor may be difficult to observe clearly if its depth is small.

\section{Acknowledgment}

The author would like to thank the financial support of the Centre National de la Recherche Scientifique and the laboratory 
LTDS UMR-CNRS 5513 (Laboratoire de Tribologie et Dynamique des Systèmes) in carrying out this research.

\section{References}

[1] Gasch, R., 1993, "A Survey of the Dynamic Behaviour of a Simple Rotating Shaft With a Transverse Crack," J. Sound Vib., 160(2), pp. 313-332.

[2] Dimarogonas, A., 1996, "Vibration of Cracked Structures: A State of the Art Review," Eng. Fract. Mech., 55, pp. 831-857.

[3] Wauer, J., 1990, "Dynamics of Cracked Rotors: Literature Survey," Appl. Mech. Rev., 43, pp. 13-17.

[4] Sekhar, A., and Prabhu, B., 1998, "Condition Monitoring of Cracked Rotors Through Transient Response,” Mech. Mach. Theory, 33(8), pp. 1167-1175.

[5] Darpe, K., Gupta, K., and Chawla, A., 2003, "Experimental Investigations of the Response of a Cracked Rotor to Periodic Axial Excitation," J. Sound Vib. 260(2), pp. 265-286.

[6] Pennacchi, P., Bachschrnid, N., and Vania, A., 2006, "A Model-Based Identification Method of Transverse Cracks in Rotating Shafts Suitable for Industrial Machines," Mech. Syst. Signal Process., 20(8), pp. 2112-2147.

[7] Ishida, Y., and Inoue, T., 2006, "Detection of a Rotor Crack Using a Harmonic
Excitation and Nonlinear Vibration Analysis,” ASME J. Vibr. Acoust., 128(6), pp. 741-749.

[8] Davies, W. G. R., and Mayes, I. W., 1984, "The Vibrational Behaviour of a Multi-Shaft, Multi-Bearing System in the Presence of a Propagating Transverse Crack," Trans. ASME, J. Vib., Acoust., Stress, Reliab. Des., 106, pp. $146-153$.

[9] Mayes, I. W., and Davies, W. G. R., 1984, "Analysis of the Response of a Multi-Rotor-Bearing System Containing a Transverse Crack in a Rotor," Trans. ASME, J. Vib., Acoust., Stress, Reliab. Des., 106, pp. 139-145.

[10] Adewusi, S., and Al-Bedoor, B., 2002, "Experimental Study on the Vibration of an Overhung Rotor With a Propagating Transverse Crack," Shock Vib., 9, p. 91-104.

[11] Sinou, J.-J., and Lees, A. W., 2007, “A Non-Linear Study of a Cracked Rotor," Eur. J. Mech. A/Solids, 26(1), pp. 152-170.

[12] Sinou, J.-J., and Lees, A. W., 2005, "Influence of Cracks in Rotating Shafts," J. Sound Vib., 285(4-5), pp. 1015-1037.

[13] Sinou, J.-J., 2008, "Detection of Cracks in Rotor Based on the $2 \times$ and $3 \times$ Super-Harmonic Frequency Components and the Crack-Unbalance Interactions," Commun. Nonlinear Sci. Numer. Simul., 13(9), pp. 2024-2040.

[14] Sinou, J.-J., 2008, "Effects of a Crack on the Stability of a Non-Linear Rotor System,” Int. J. Non-Linear Mech., 42, pp. 959-972. 